\title{
Germination triggers of Metarhizium anisopliae conidia are related to host species
}

\author{
Raymond J. St Leger, Michael J. Bidochka and Donald W. Roberts
}

Author for correspondence: Raymond J. St Leger. Tel. +1 607254 1252. Fax: +1 6072541242.

Boyce Thompson Institute for Plant Research at Cornell University, Tower Road, Ithaca, New York 148531801, USA
The role of selectable strain variations in the development of pathogen strategies was examined using lines of Metarhizium anisopliae isolated from homopteran (isolate 549) or coleopteran (isolate 808 ) hosts. Conidia of strain 549 germinated in either alanine, glucose, cyclic AMP or the phosphodiesterase inhibitor 3-isobutyl-1-methylxanthine (IBMX). The non-metabolizable glucose analogues, 3-0-methylglucose and 6-deoxyglucose, did not allow germination by themselves but stimulated germination when added to IBMX. By contrast, 2-deoxyglucose (dGIc) blocked germination on glucose or IBMX and inhibited hyphal growth on other carbon sources including alanine and glycerol. Conidia of strain $\mathbf{8 0 8}$ germinated rapidly in alanine but responded slowly to glucose or IBMX in the medium and were resistant to the growth inhibitory effects of dGIc. Radioactive dGIc was taken up by conidia of strains 549 and 808 at similar rates and was recovered mainly as 2-deoxyglucose 6-phosphate. Competition experiments utilizing both strains demonstrated that glucose, dGIc and 3-0-methylglucose were transported by the same system. Fructose was much less able than glucose to inhibit uptake of dGlc indicating that fructose is taken up by a different transport system than that for glucose. It is unlikely, therefore, that the resistance of strain 808 to dGIc is explained by reduced sugar transport compared with strain 549 but that strains 549 and 808 differ in the regulation of carbon metabolism with some systems in strain 808 showing resistance to the catabolite-repressing effects of glucose. Apparently, catabolite repression is subdivided into different segments as glucose inhibited the derepression of a number of catabolite repressible enzymes in strain 808, including the pathogenicity determinant protease Pr1. The same effect was produced by dGIc but not by 3-0-methylglucose, indicating that the trigger for catabolite repression occurs at the level of transport-associated glucose phosphorylation. A comparative study of $\mathbf{2 6}$ isolates indicated that most lines from coleopteran hosts were dGlc resistant and germinated poorly on glucose. Conversely, isolates germinating well on glucose (mostly from hemipteran and lepidopteran hosts) were dGlc susceptible.

Keywords: Metarbizium anisopliae, glucose analogues, catabolite repression, conidial germinaton

\section{INTRODUCTION}

The penetration of insect cuticle by entomopathogenic fungi often requires, in addition to spore germination, the precise differentiation of an organized series of structures.

Abbreviations: CzD, Czapek Dox agar; dGlc, 2-deoxyglucose; dGlcPO 4 , 2deoxyglucose 6-phosphate; IBMX, 3-isobutyl-1-methylxanthine; PDA, potato dextrose agar; YEM, yeast extract medium.
Of these, the appressorium is developmentally the first and most important structure formed in preparation for host colonization.

Entomopathogenic fungi have not been studied systematically to search for the molecular events leading to spore germination and differentiation of appressoria, but processes that influence penetration include perception of stimuli, transmission of the differentiation signals, activation of macromolecular biosynthesis, and differential 
Table 1. Effects of glucose, glucose derivatives and second messengers on the growth of $M$. anisopliae strains 549 and 808

\begin{tabular}{|c|c|c|c|c|c|c|c|c|c|c|c|c|}
\hline \multirow[t]{4}{*}{ Addition } & \multicolumn{6}{|c|}{ Strain 549} & \multicolumn{6}{|c|}{ Strain 808} \\
\hline & \multicolumn{2}{|c|}{$\begin{array}{l}\text { Percentage } \\
\text { germination }\end{array}$} & \multicolumn{2}{|c|}{$\begin{array}{l}\text { Mean length }( \pm \mathrm{SE}) \\
\text { of germ-tube }(\mu \mathrm{m})\end{array}$} & \multirow{2}{*}{\multicolumn{2}{|c|}{$\begin{array}{l}\text { Petcentage } \\
\text { differentiation } \\
\text { of appressoria }\end{array}$}} & \multicolumn{2}{|c|}{$\begin{array}{l}\text { Percentage } \\
\text { germination }\end{array}$} & \multicolumn{2}{|c|}{$\begin{array}{l}\text { Mean length }( \pm \mathrm{SE}) \\
\text { of germ-tube }(\mu \mathrm{m})\end{array}$} & \multirow{2}{*}{\multicolumn{2}{|c|}{$\begin{array}{c}\text { Percentage } \\
\text { differentiation } \\
\text { of appressoria }\end{array}$}} \\
\hline & $18 \mathrm{~h}$ & $24 \mathrm{~h}$ & $18 \mathrm{~h}$ & $24 \mathrm{~h}$ & & & $18 \mathrm{~h}$ & $24 \mathrm{~h}$ & $18 \mathrm{~h}$ & $24 \mathrm{~h}$ & & \\
\hline & & & & & $18 \mathrm{~h}$ & $24 \mathrm{~h}$ & & & & & $18 \mathrm{~h}$ & $24 \mathrm{~h}$ \\
\hline None & & 0 & - & & - & - & & 0 & - & - & - & \\
\hline $\operatorname{cAMP}(5 \mathrm{mM})$ & 34 & 76 & $14 \pm 6$ & $22 \pm 9$ & 16 & 32 & 12 & 32 & $12 \pm 5$ & $19 \pm 5$ & 0 & 2 \\
\hline Adenosinc $(5 \mathrm{mM})$ & 22 & 83 & $17 \pm 3$ & $28 \pm 7$ & 5 & 16 & 24 & 59 & $16 \pm 5$ & $34 \pm 8$ & 0 & 0 \\
\hline IBMX $(5 \mathrm{mM})$ & 9 & 17 & $4 \pm 1$ & $6 \pm 2$ & 0 & 0 & 0 & 4 & 0 & $4 \pm 0.5$ & 0 & 0 \\
\hline Alanine $(0.5 \%)$ & 45 & 87 & $60 \pm 12$ & $93 \pm 7$ & 24 & 62 & 28 & $>90$ & $53 \pm 9$ & $78 \pm 11$ & 8 & 31 \\
\hline Glucose $(0 \cdot 1 \%)$ & 40 & 78 & $36 \pm 9$ & $66 \pm 8$ & 6 & 27 & 3 & 13 & $12 \pm 4$ & $32 \pm 8$ & 0 & 0 \\
\hline$+\mathrm{cAMP}(5 \mathrm{mM})$ & $>90$ & $>90$ & $87 \pm 16$ & $116 \pm 27$ & 52 & 74 & 48 & 73 & $27 \pm 5$ & $54 \pm 14$ & 0 & 11 \\
\hline + Adenosine $(5 \mathrm{mM})$ & 72 & $>90$ & $63 \pm 7$ & $82 \pm 17$ & 22 & 34 & 27 & 62 & $47 \pm 8$ & $59 \pm 11$ & 0 & 8 \\
\hline +2-Deoxyglucose $(0.5 \%)$ & $<1$ & $<1$ & 0 & 0 & 0 & 0 & 5 & 34 & $9 \pm 3$ & $19 \pm 4$ & 0 & 0 \\
\hline +6-Deoxyglucose $(0.5 \%)$ & 23 & 47 & $29 \pm 8$ & $47 \pm 13$ & 3 & 7 & 2 & 2 & $6 \pm 1$ & $8 \pm 3$ & 0 & 0 \\
\hline+ Alanine $(0.5 \%)$ & $>90 \%$ & $>90 \%$ & $64 \pm 12$ & $110 \pm 17$ & 62 & $>90$ & $>90 \%$ & $>90 \%$ & $62 \pm 10$ & $87 \pm 14$ & 22 & 73 \\
\hline 2-Deoxyglucose (0.5\%) & & 0 & 0 & 0 & 0 & 0 & 0 & 2 & 0 & $6 \pm 2$ & 0 & 0 \\
\hline$+\mathrm{CAMP}(5 \mathrm{mM})$ & $<1$ & $<1$ & 0 & 0 & 0 & 0 & 0 & 2 & 0 & $11 \pm 5$ & 0 & 0 \\
\hline+ Adenosine $(5 \mathrm{mM})$ & $<1$ & $<1$ & 0 & 0 & 0 & 0 & 17 & 43 & $6 \pm 2$ & $13 \pm 5$ & 0 & 0 \\
\hline$+\operatorname{IBMX}(5 \mathrm{mM})$ & $<1$ & $<1$ & 0 & 0 & 0 & 0 & 7 & 15 & $14 \pm 3$ & $18 \pm 5$ & 0 & () \\
\hline+ Alanine $(0.5 \%)$ & 72 & 84 & $22 \pm 11$ & $48 \pm 8$ & 18 & 23 & 64 & 81 & $43 \pm 9$ & $82 \pm 12$ & 13 & 28 \\
\hline 6-Deoxyglucose (0.5\%) & $<1$ & 2 & 0 & $6 \pm 1$ & 0 & 0 & 0 & 0 & 0 & 0 & 0 & 0 \\
\hline +cAMP $(5 \mathrm{mM})$ & 50 & 72 & $7 \pm 1$ & $16 \pm 2$ & 0 & 8 & 12 & 37 & $9 \pm 2$ & $15 \pm 2$ & 0 & 0 \\
\hline$+1 \mathrm{BMX}(5 \mathrm{mM})$ & 12 & 3 & $8 \pm 1$ & $15 \pm 2$ & 0 & 0 & 0 & 5 & 0 & $6 \pm 0.5$ & 0 & 0 \\
\hline 3-O-Methylglucose (0.5\%) & 2 & 4 & 0 & $4 \pm 0 \cdot 5$ & 0 & 0 & 0 & 0 & 0 & 0 & 0 & 0 \\
\hline tcAMP $(5 \mathrm{mM})$ & 45 & 71 & $6 \pm 2$ & $17 \pm 3$ & 0 & 3 & 0 & 0 & 0 & 0 & 0 & 0 \\
\hline$+\operatorname{IBMX}(5 \mathrm{mM})$ & 15 & 36 & $7 \pm 1$ & $19 \pm 4$ & 0 & 6 & 0 & 0 & 0 & 0 & 0 & 0 \\
\hline Glycerol (1\%) & 78 & $>90$ & $42 \pm 6$ & $95 \pm 7$ & 18 & 64 & 74 & $>90$ & $34 \pm 8$ & $53 \pm 13$ & 9 & 51 \\
\hline + Glucose $(0.5 \%)$ & $>90$ & $>90$ & $74 \pm 18$ & $118 \pm 23$ & 17 & 30 & $>90$ & $>90$ & $67 \pm 9$ & $104 \pm 16$ & 11 & 47 \\
\hline +2-Deoxyglucose (0.5\%) & 81 & $>90$ & $27 \pm 7$ & $38 \pm 7$ & 7 & 14 & 71 & 82 & $37 \pm 10$ & $54 \pm 15$ & 11 & 42 \\
\hline +6-Deoxyglucose $(0.5 \%)$ & 85 & $>90$ & $33 \pm 8$ & $61 \pm 9$ & 6 & 11 & 60 & 73 & $25 \pm 4$ & $56 \pm 12$ & 8 & 40 \\
\hline
\end{tabular}

gene expression. Germlings of the Metarbizium anisopliae isolate ME1 (now given the ARSEF number 2575) used in our previous studies possess many membrane-bound cell receptor systems [e.g. a GTP-regulated adenylate cyclase, tyrosine protein kinases, serine and threonine protein kinases, phosphoprotein phosphatase, and an ATPase (St Leger et al., 1989a, b, 1990a, b, c)] that act to change second messenger levels (cAMP or $\mathrm{Ca}^{2+}$ ) or are themselves activated by second messengers to trigger differentiation. Fluctuations in the relative levels of cAMP and $\mathrm{Ca}^{2+}$ control the morphology of $M$. anisopliae ARSEF 2575 via changes in nuclear division, the cytoskeleton and the cell wall (St Leger et al., 1990a). A model for appressorium formation has been proposed in which a localized change in transmembrane potential produced by deformation of the plastic hyphal tip, i.e. the thigmotropic induction signal, affects the levels of $\mathrm{Ca}^{2+}$ and cAMP disrupting apically localized wall synthesis. Subsequent differential $\mathrm{Ca}^{2+}$ redistribution in the cell enlargement zone causes germ-tube expansion by cytoplasmic pressure against an expanding area of primary wall produced by uniformly dispersed wall synthesis (St Leger et al., 1991).

To date, our model does not encompass the role of nutrients in stimulating differentiation-an important omission since patterns of growth and differentiation among 114 isolates of $M$. anisopliae were frequently related to the nutrient conditions pertaining to their hosts $(\mathrm{St}$
Leger et al., 1992). For example, in the case of Homoptera, endogenous nutrients are likely to be supplemented by insect secretions rich in sugars, and it is interesting that in contrast to coleopteran-derived isolates some lines isolated from Homoptera demonstrated good germination and production of appressoria in glucose media. These observations suggest that host recognition mechanisms are keyed to nutrient levels available on appropriate host cuticles (St Leger et al., 1991). Genetic similarities determined by allozyme analysis provided evidence that Brazil and Colombia contain a common, widely dispersed genotypic class (class 14). The lines of class 14 , isolated from several insect orders including Homoptera (e.g. ARSEF 549) demonstrated similar growth patterns (good germination and high levels of differentiation) in yeast extract media or glucose media. The exception was ARSEF 808, which germinated poorly in glucose media, and was the only line from class 14 derived from a coleopteran host.

Evidently, being in the same genotypic class, defined by a series of electrophoretic phenotypes, does not rule out pathogenic diversity in patterns of growth and differentiation. This provides an opportunity for comparative studies on differences in perception mechanisms, transduction chains, and physiological responses, against a similar genetic background. We have initiated such a study to determine whether unifying themes exist between 

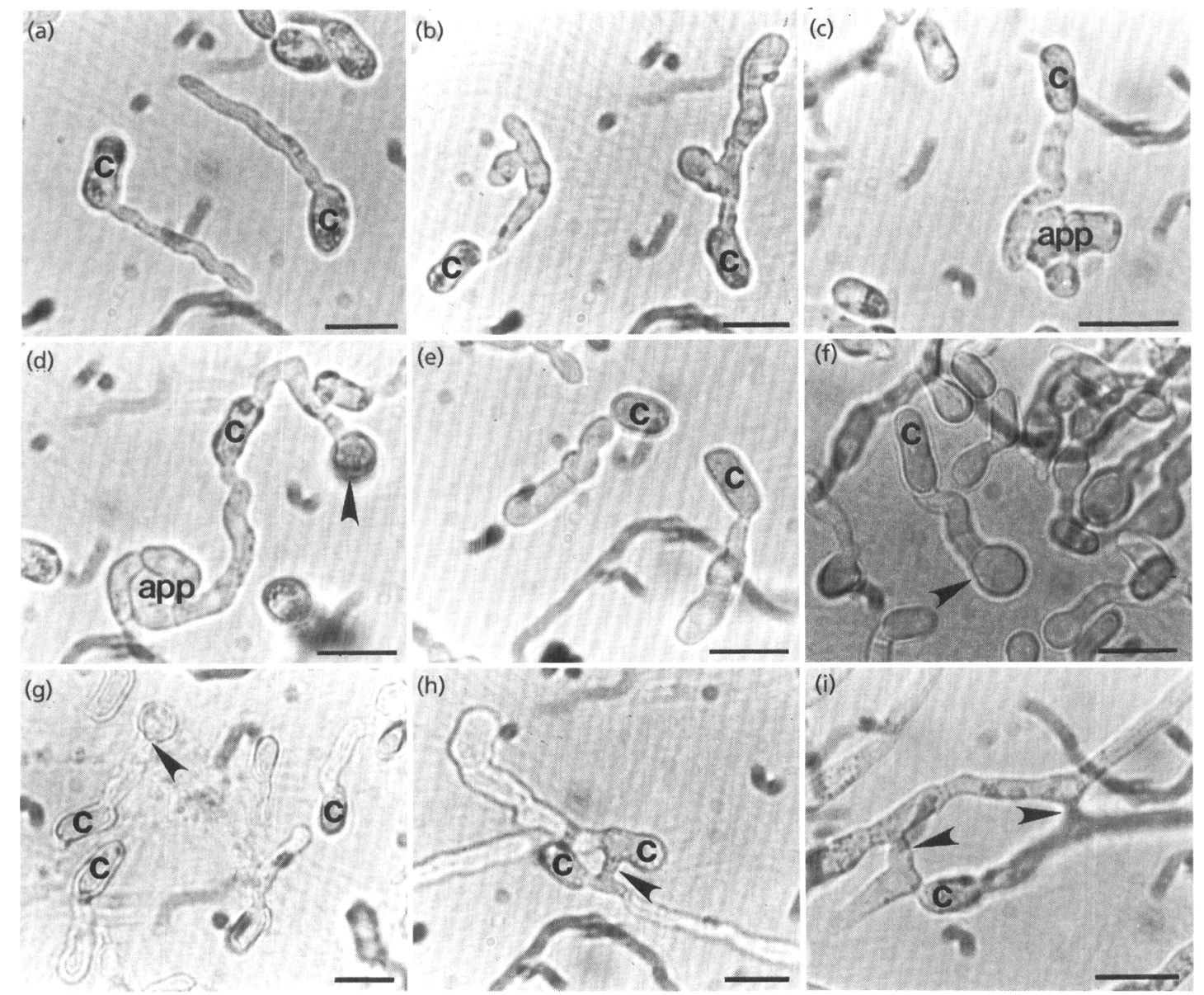

\begin{abstract}
Fig. 1. Micrographs of $M$. anisopliae (ARSEF 549) conidia germinated in basal medium ( $20 \mathrm{mM}$ potassium phosphate buffer, $\mathrm{pH} 6.7,0.2 \% \mathrm{NaNO}_{3}, 0.05 \% \mathrm{MgSO}_{4}$ ) on polystyrene for $22 \mathrm{~h}(\mathrm{a}-\mathrm{h})$. Basal medium was supplemented with (a) $0.1 \%$ glucose, (b, $c, d) 0.1 \%$ glucose +5 mM cAMP (note terminal blastospore-like cell indicated by arrowhead), (e) $0.5 \%$ alanine, (f, g) $0.5 \%$ alanine $+0.5 \%$ dGlc [note swelling of the tip cells (indicated by arrowheads) delineated from hyphae by septa]. For both strain $549(\mathrm{~h})$ and strain 808 (i) anastomosis was frequently observed between hyphae (indicated by arrowheads). app, Appressorium; c, conidium. Bars, $10 \mu \mathrm{m}$.
\end{abstract}

the different ways in which two isolates in class 14 (549 and 808 ) respond to environmental signals.

\section{METHODS}

Organisms and growth. The 26 isolates of Metarbizium anisopliae used in this study were described by St Leger et al. (1992). Conidia were obtained from $11 \mathrm{~d}$ PDA cultures incubated at $27^{\circ} \mathrm{C}$. Conidia were washed from the agar surface, centrifuged and resuspended twice in distilled water. To test the isolates' nutritional requirements for germination and differentiation, conidia were germinated in $5.5 \mathrm{~cm}$ polystyrene dishes (St Leger et al., 1989a) containing basal medium $(20 \mathrm{mM}$ potassium phosphate buffer, $\mathrm{pH} 6.7,0.2 \% \mathrm{NaNO}_{3}, 0.05 \%$ $\mathrm{MgSO}_{4}$ ) and carbon source as specified. One hundred spores from each of four replicates were scored to assess germination and differentiation frequency. Where solid medium was required, $1.5 \%(\mathrm{w} / \mathrm{v}$ ) noble agar (Difco) was added to the basal medium. Supplements were filter sterilized $(0 \cdot 22 \mu \mathrm{m})$ and added to the medium at $50^{\circ} \mathrm{C}$.

Preparation and analysis of culture filters. Standardized mycelial inocula ( $5 \mathrm{~g}$ wet $\mathrm{wt}$ ) from $48 \mathrm{~h}$ Sabouraud dextrose broth cultures (St Leger et al., 1991) were incubated with shaking (100 r.p.m.) for $5 \mathrm{~h}$ in $100 \mathrm{ml}$ chitin medium $(1 \%(\mathrm{w} / \mathrm{v})$ chitin, $0.02 \% \mathrm{KH}_{2} \mathrm{PO}_{4}, 0.01 \% \mathrm{MgSO}_{4}, \mathrm{pH}$ 6) supplemented with carbon and/or nitrogen sources at $0 \cdot 2-2 \%(\mathrm{w} / \mathrm{v})$. Chymoelastase activity ( $\operatorname{Pr} 1)$ in culture filtrates (Whatman No. 1 filter paper) was determined using succinyl-alanine-alanineproline-phenylalanine $p$-nitroanilide as substrate (St Leger $e t$ al., 1988). Filtrates were also characterized using the 19 enzyme activities in the semi-quantitative API ZYM system as described previously (St Leger et al., 1986b).

Quantitative measurements of resistance to dGlc were made by inoculating $50 \mathrm{ml}$ standing cultures (basal medium with fructose or glucose at $1 \%(\mathrm{w} / \mathrm{v})$ and various concentrations of dGlc) with $10^{6}$ conidia, incubating the cultures for $3 \mathrm{~d}$ at $25^{\circ} \mathrm{C}$, harvesting the mycelial mat and determining dry weight.

Uptake of $\left[{ }^{14} \mathrm{C}\right]$ dGIc. Aliquots $(2.5 \mathrm{ml})$ of a conidial suspension $\left(5 \times 10^{6}\right.$ spores $\left.\mathrm{ml}^{-1}\right)$ in basal medium were shaken for $7 \mathrm{~h}$ at $25^{\circ} \mathrm{C}$ and supplemented with $\left[{ }^{14} \mathrm{C}\right.$ ]dGlc [ final concn $20 \mu \mathrm{Ci} \mathrm{ml}{ }^{-1}$ $\left.\left(740 \mathrm{kBq} \mathrm{ml}^{-1}\right)\right]$. At intervals, a $1 \mathrm{ml}$ sample of each conidial suspension was spotted directly onto a glass-fibre (Whatman $\mathrm{GF} / \mathrm{A}$ ) disc. The conidia were washed (five $\times 20 \mathrm{ml}$ ) with $0.2 \mathrm{M}$ potassium phosphate buffer containing $\mathrm{KCl}(0 \cdot 1 \mathrm{M})$ and counted 
with their filters in $6 \mathrm{ml}$ of Cytoscint (ICN) cocktail using a Beckmann LS 5801 scintillation counter. Adsorption of radioactivity to conidia and filters was also determined in cells incubated on ice. These values were subtracted from experimental samples to give the total uptake of $\left[{ }^{14} \mathrm{C}\right] \mathrm{dGlc}$ by conidia. In competition studies, conidia were exposed to glucose $(1-10 \mathrm{mM}), 3-O$-methylglucose $(10 \mathrm{mM})$ or fructose $(10 \mathrm{mM})$, and labelled dGlc simultaneously, and the rate of uptake determined.

The ability of mycelia to transport $\left[{ }^{14} \mathrm{C}\right] \mathrm{dGlc}$ or methyl $\left[{ }^{14} \mathrm{C}\right]$ glucose was assayed using agar cultures grown for $3 \mathrm{~d}$ with or without unlabelled dGlc and glucose or fructose as carbon sources. Mycelia were scraped from media with a razor blade, weighed and suspended in distilled water. The cells were harvested by filtration, washed thoroughly with water, and suspended at a density of 1-3 $\mathrm{mg}$ (dry wt) $\mathrm{ml}^{-1}$ in basal medium supplemented with methyl[ $\left[{ }^{14} \mathrm{C}\right]$ glucose or $\left[{ }^{14} \mathrm{C}\right] \mathrm{dGl}$ $\left(20 \mu \mathrm{Ci} \mathrm{ml} l^{-1}\right)$. At intervals, samples were collected and washed as described for conidia, dried overnight, weighed and counted with Cytoscint.

Cell-free extracts of conidia or mycelia exposed to labelled glucose analogues for $0 \cdot 5-2 \mathrm{~h}$ were obtained by harvesting cells: on a HAWP Millipore filter, washing as described above. boiling cells for $10 \mathrm{~min}$ in $0.5 \mathrm{ml}$ distilled water and centrifugation $\left(20000 \mathrm{~g}, 15 \mathrm{~min}\right.$ at $\left.4{ }^{\circ} \mathrm{C}\right)$. Extracts were chromatographed on Whatman silica gel thin layer plates in $\mathrm{n}$ propanol/ammonia/water (6:1:3, by vol.). Spots of methyl $\left[{ }^{14} \mathrm{C}\right]$ glucose, $\left[{ }^{14} \mathrm{C}\right] \mathrm{dGlc}$ and its metabolites were localized with ammonium molybdate/perchloric acid spray (Bourret, 1987) or by placing dried chromatograms adjacent to X-OmatAR film at room temperature for $2-3 \mathrm{~d}$.

Chemicals. 3-O-Methyl-D- $\left[\mathrm{U}^{14} \mathrm{C}\right] \mathrm{glucose}$ was purchased from Amersham. 2-[U- $\left.{ }^{14} \mathrm{C}\right]$ deoxy-D-glucose was from NEN. Yeast extract was from Difco. All other reagents, chemicals and nutrients were from Sigma.

\section{RESULTS}

\section{Growth characteristics}

Data from a comparative study of germination and appressorium formation of $M$. anisopliae strains 549 and 808 under different nutrient conditions are shown in Table 1. Strain 549 germinated well on glucose and subsequently produced moderate levels of appressoria. By contrast, strain 808 germinated poorly in glucose media and did not produce appressoria. cAMP allowed germination of both isolates but only strain 549 produced appressoria. Adenosine also activated spores of both isolates indicating that the effect was not specific to cyclic nucleotides. Significant growth on cAMP and adenosine indicates that they may function as a nutrient source. However, the cyclic nucleotide phosphodiesterase inhibitor IBMX allowed significant germination of strain 549 (but not 808) without extensive hyphal growth suggestive of a specific cAMP activation event. The effects of glucose on germination and differentiation were greatly potentiated by the presence of cAMP or adenosine $(P<0.01)$. The appearance of appressoria produced by each strain also varied with growth medium. Strain 549, which germinated on both glucose and glucose supplemented with cAMP produced larger, often branching, appressoria on the more complex medium (compare Fig. $1 \mathrm{a}$ with Fig. 1b, c and d). Both strains germinated well and produced appressoria with alanine, a nitrogenous nutrient, and the non-fermentable carbon source glycerol.

The glucose analogues dGlc, 6-deoxyglucose, and 3-Omethylglucose did not allow germination of either strain alone. However, supplementing IBMX with 6-deoxyglucose or 3-O-methylglucose stimulated germination compared with IBMX alone $(P<0 \cdot 01$ in both instances). Unlike 6-deoxyglucose, dGlc blocked germination of strain 549 on glucose, cAMP and adenosine. dGlc was not inherently toxic because it did not inhibit germination on alanine or glycerol. However, in the presence of dGlc and alanine, many conidia of strain 549 produced terminal blastospore-like cells which were delineated from hyphae by a septum (Fig. 1f, g). These were occasionally seen in other media (Fig. 1d) but rarely with alanine alone (Fig. 1e). By contrast, strain 808 appeared to be unaffected by dGlc in combination with any of the other carbon sources tested (Table 1).

For both strains 549 and 808 , anastomoses were frequently observed between hyphae (Fig. 1h, i).

\section{Effects of dGlc on M. anisopliae cultures in liquid or solid media}

Fig. 2 shows that the presence or absence of dGlc in the liquid culture medium did not exert a major influence on total mycelial growth of line 808. By contrast, dGic $(16 \mathrm{mM})$ inhibited growth of strain 549 on fructose and glucose by $77 \%$ and $33 \%$, respectively.

As liquid cultures do not allow sporulation, further observations were performed on agar plates containing different carbon sources and dGlc (Table 2 and Fig. 3). The addition of dGlc to cultures of strain 808 decreased

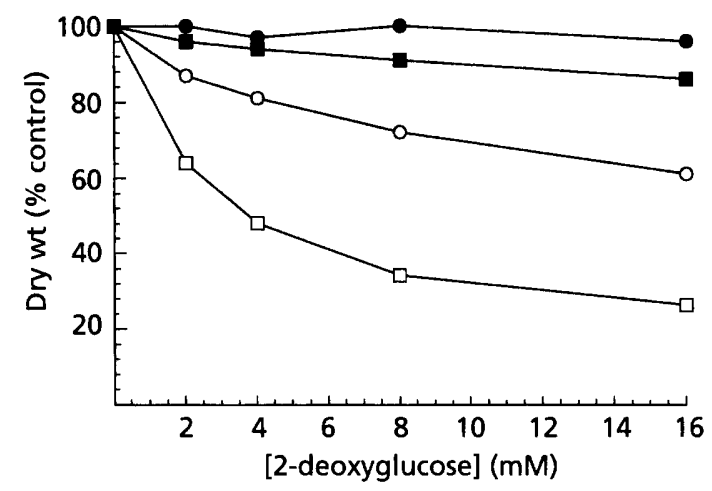

Fig. 2. Inhibition of growth by 2-deoxyglucose. Conidia $\left(10^{6}\right)$ of ARSEF 549 (open symbols) or ARSEF 808 (closed symbols) were inoculated into standing cultures [basal medium with fructose $(\square, \square)$ or glucose $(O, 0)$ at $1 \%(w / v)$ and various concentrations of dGIc] and incubated for $3 \mathrm{~d}$ at $25^{\circ} \mathrm{C}$. Mycelial mats were harvested and weighed. Each point is the mean of three replicates. Variation around the mean was less than $7.5 \%$ in each instance. 
Table 2. Growth and sporulation by $M$. anisopliae strains 549 and 808 on agar medium containing various carbon sources with or without dGlc, $4 \mathrm{~d}$ after inoculation

Results are means $\pm \mathrm{SE}$ for eight replicates per test.

\begin{tabular}{|c|c|c|c|c|c|c|c|c|}
\hline \multirow{3}{*}{$\begin{array}{l}\text { Carbon } \\
\text { source } \\
(1 \%, w / v)\end{array}$} & \multicolumn{4}{|c|}{ Strain 549} & \multicolumn{4}{|c|}{ Strain 808} \\
\hline & \multicolumn{2}{|c|}{$-\mathrm{dGlc}$} & \multicolumn{2}{|c|}{ + dGlc } & \multicolumn{2}{|c|}{ - dGlc } & \multicolumn{2}{|c|}{ + dGlc } \\
\hline & $\begin{array}{c}\text { Growth } \\
(\mathrm{mm})\end{array}$ & $\begin{array}{l}\text { Conidial } \\
\text { density* }\end{array}$ & $\begin{array}{c}\text { Growth } \\
(\mathrm{mm})\end{array}$ & $\begin{array}{l}\text { Conidial } \\
\text { density* }\end{array}$ & $\begin{array}{c}\text { Growth } \\
(\mathrm{mm})\end{array}$ & $\begin{array}{l}\text { Conidial } \\
\text { density* }\end{array}$ & $\begin{array}{l}\text { Growth } \\
(\mathrm{mm})\end{array}$ & $\begin{array}{l}\text { Conidial } \\
\text { density* }\end{array}$ \\
\hline Glucose & $13 \cdot 3 \pm 0 \cdot 36$ & ++ & $3 \cdot 4 \pm 0 \cdot 2$ & - & $13 \cdot 6 \pm 0 \cdot 45$ & ++ & $11 \cdot 5 \pm 0 \cdot 30$ & + \\
\hline Fructose & $11 \cdot 2 \pm 0 \cdot 51$ & + & $<0.5$ & - & $10 \cdot 92 \pm 0.27$ & ++ & $9 \cdot 2 \pm 0 \cdot 21$ & - \\
\hline Galactose & $10 \cdot 5 \pm 0 \cdot 37$ & + & $1 \cdot 1 \pm 0 \cdot 02$ & - & $11 \cdot 3 \pm 0 \cdot 61$ & + & $11 \cdot 8 \pm 0 \cdot 18$ & - \\
\hline Mannose & $12 \pm 0 \cdot 32$ & +++ & $1 \cdot 2 \pm 0 \cdot 01$ & - & $12 \cdot 7 \pm 0 \cdot 45$ & +++ & $11 \cdot 7 \pm 0 \cdot 24$ & - \\
\hline Xylose & $11 \cdot 7 \pm 0.34$ & + & $<0.5$ & - & $10 \cdot 3 \pm 0 \cdot 25$ & + & $9 \cdot 5 \pm 0 \cdot 22$ & - \\
\hline Raffinose & $11 \cdot 5 \pm 0 \cdot 41$ & + & $1 \cdot 1 \pm 0 \cdot 02$ & - & $11 \cdot 2 \pm 0 \cdot 34$ & ++ & $7 \cdot 5 \pm 0 \cdot 04$ & - \\
\hline Ribose & $11 \cdot 1 \pm 0 \cdot 47$ & +++ & $<0.5$ & - & $8 \cdot 5 \pm 0 \cdot 21$ & +++ & $9 \cdot 2 \pm 0 \cdot 08$ & - \\
\hline Sorbose & $2 \cdot 5 \pm 0.04$ & - & $<0.5$ & - & $3 \cdot 7 \pm 0 \cdot 1$ & - & $7 \cdot 0 \pm 0 \cdot 04$ & - \\
\hline Alanine & $10 \cdot 5 \pm 0.33$ & ++ & $1 \cdot 0 \pm 0 \cdot 02$ & - & $11 \cdot 8 \pm 0 \cdot 25$ & ++ & $9 \cdot 2 \pm 0 \cdot 05$ & - \\
\hline Sodium acetate & $9 \cdot 7 \pm 0.38$ & + & $2 \cdot 3 \pm 0 \cdot 05$ & - & $9 \cdot 5 \pm 0 \cdot 14$ & - & $9 \cdot 6 \pm 0.06$ & - \\
\hline Glycerol & $8 \cdot 2 \pm 0 \cdot 05$ & ++ & $1.5 \pm 0.04$ & - & $13 \cdot 7 \pm 0 \cdot 18$ & ++ & $11 \cdot 5 \pm 0 \cdot 10$ & + \\
\hline
\end{tabular}

* An arbitrary scale of increasing conidial density: - , none; + , poor; ++ , fair; +++ , good.

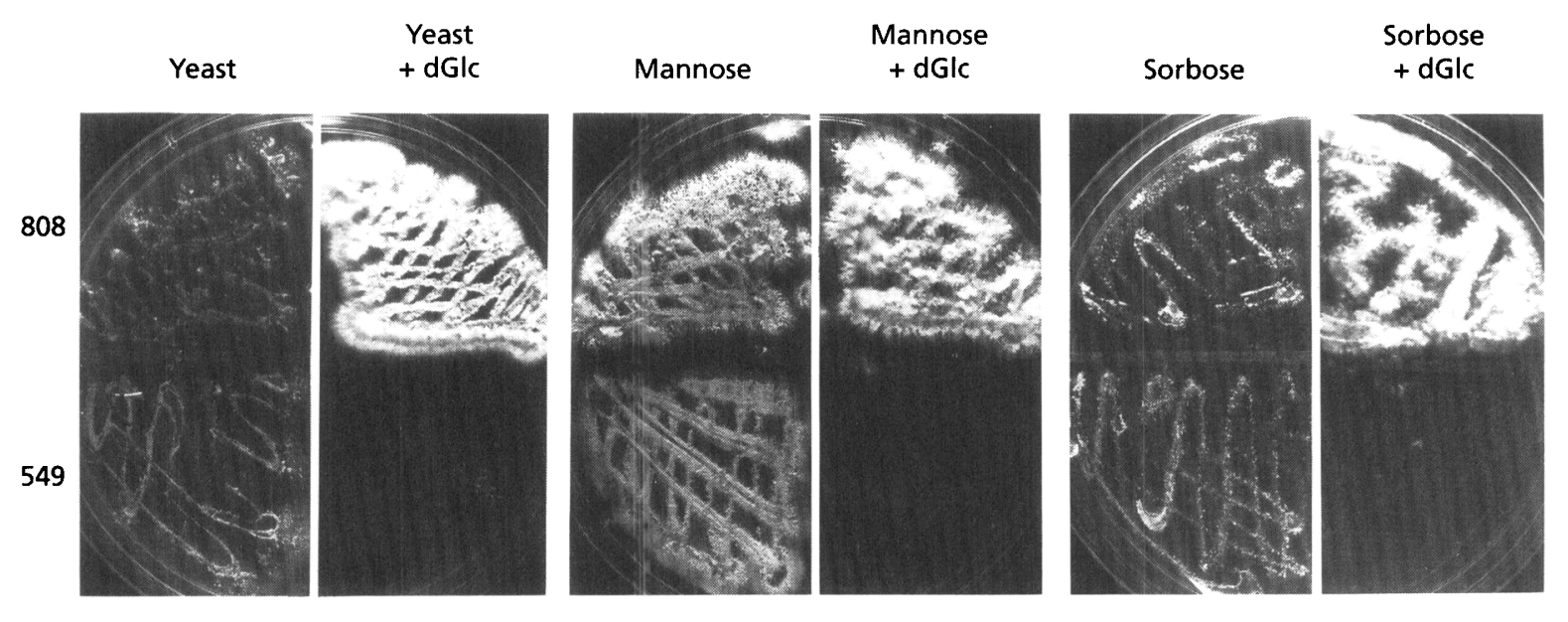

Fig. 3. Growth of $M$. anisopliae, strains 549 and 808 on YEM ('yeast'), mannose and sorbose with or without dGIc, $4 \mathrm{~d}$ after inoculation. dGlc reduces growth of strain 549 and stimulates production of aerial hyphae by strain 808 .

the accumulation of conidia and stimulated the elongation of aerial hyphae. Otherwise, strain 808 grew well with dGlc on fermentable sugars, glycerol and sodium acetate (non-fermentable substrates) and alanine. By contrast, dGlc greatly reduced growth of strain 549 on all of these substrates. In addition, dGlc caused production of black pigment (melanin?) on glycerol and, to a lesser extent, on sodium acetate.

\section{Uptake of dGlc}

We measured the uptake of dGlc by strains 549 and 808 to test whether the resistance of strain 808 to toxic analogues is caused by a reduction in sugar transport. Conidia of strain 808 took up $\sim 30 \%$ less $\left[{ }^{14} \mathrm{C}\right] \mathrm{dGlc}$ compared with strain 549 over a $30 \mathrm{~min}$ period $(P<0.05)$ (Table 3$)$. The uptake of labelled dGlc by both strains was progressively reduced by the addition of increasing concentrations of glucose or $10 \mathrm{mM} 6$-deoxyglucose indicating that glucose, 6-deoxyglucose and dGlc probably share a common entry system. Fructose did not repress uptake.

To test whether growth in the presence of dGlc alters transport systems, mycelia of strain 808 were harvested from agar plates containing fructose (derepressing conditions) or glucose (repressing conditions) with or with- 
out dGlc (Table 4). Uptake of labelled substrate by fructose-grown mycelia was $40 \%$ higher than by glucosegrown cultures. Supplementing glucose cultures with dGlc further lowered mycelial uptake of substrate by ca. $40 \%$ compared to glucose alone $(P<0.01$ in both instances).

To determine if dGlc is metabolized by $M$. anisopliae, as by other organisms, to 2-deoxyglucose phosphate (Moore, 1981), extracts of conidia or mycelia exposed to labelled $\mathrm{dGlc}$ for $2 \mathrm{~h}$ were chromatographed (Fig. 4). Heating conidia of strains 808 or 549 in water extracted more than $95 \%$ of the label; extraction from mycelia was $\geqslant 83 \%$ (Table 4). Much of the radioactivity in extracts from spores that had been fed labelled dGlc appeared on TLC along with authentic 2 -deoxyglucose phosphate. This was

Table 3. Effects of glucose, 6-deoxyglucose and fructose levels on $\left[{ }^{14} \mathrm{C}\right] \mathrm{dG}$ (c uptake by conidia of $M$. anisopliae strains 549 and 808

Conidia were exposed to labelled dGlc $\left(20 \mu \mathrm{Ci} \mathrm{m}^{-1}\right)$ for $30 \mathrm{~min}$, then aliquots of conidia were analysed for dGlc uptake.

Percentage values are given in parentheses.

\begin{tabular}{|lcc|}
\hline $\begin{array}{l}\text { Extracellular } \\
\text { sugar concn }(\mathbf{m M})\end{array}$ & \multicolumn{2}{c|}{$\begin{array}{c}\mathbf{1 0}^{\mathbf{- 3}} \times\left[{ }^{\mathbf{1 4}} \mathrm{C}\right] \mathrm{dGlc} \text { uptake } \\
\text { [c.p.m. } \pm \text { SE; } \boldsymbol{n}=\mathbf{5}]\end{array}$} \\
\cline { 2 - 3 } & Strain 549 & Strain 808 \\
\hline Glucose & & \\
0 & $265 \pm 33(100)$ & $195 \pm 26(100)$ \\
$2 \cdot 5$ & $127 \pm 21(48)$ & $82 \pm 11(48)$ \\
10 & $48 \pm 6(18)$ & $23 \pm 5(12)$ \\
50 & $6 \pm 2(2)$ & 0 \\
6-Deoxyglucose & & $39 \pm 4(20)$ \\
10 & $56 \pm 9(21)$ & \\
Fructose & & $174 \pm 17(89)$ \\
50 & $245 \pm 28(92)$ & \\
\hline
\end{tabular}

also a major product of mycelia of strain 808 grown in the presence of dGlc but some higher molecular mass products were also apparent (Fig. 4, E). By contrast, though mycelia took up labelled 3-O-methylglucose at levels similar to $\left[{ }^{14} \mathrm{C}\right] \mathrm{dGlc}$, chromatographs indicated that

\section{A $\quad$ B $C$ C D $\quad E$}

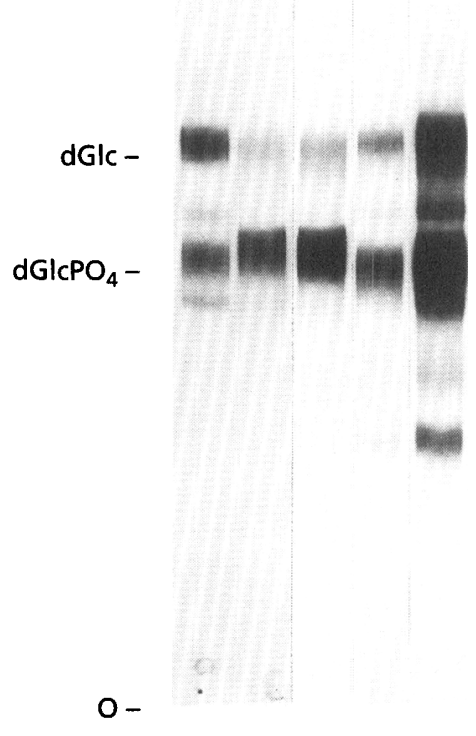

Fig. 4. Metabolism of dGlc by $M$. anisopliae. Chromatograms of hot water extracts from cells that have taken up labelled dGIc for $2 \mathrm{~h}(A-D)$ or $4 \mathrm{~h}(E)$ were developed as described in Methods. Extracts were from (A) strain 549 conidia, (B) strain 808 conidia, $(C+E)$ mycelia of strain 808 grown on $0.5 \%$ fructose $+0.5 \%$ dGIc, (D) mycelia of strain 808 grown on $0.5 \%$ glucose $+0.5 \%$ dGlc. Each experiment was repeated three times. In each case, two bands corresponding to authentic dGlc and $\mathrm{dGlCPO}_{4}$ predominated. However, their relative contribution to total radioactivity and the presence or absence of other bands was variable between replicates. $O$, origin.

Table 4. $\left[{ }^{14} \mathrm{C}\right] \mathrm{dGl}$ uptake by mycelia of $M$. anisopliae strain 808 grown on glucose or fructose in the presence of dGlc

Mycelia of strain 808 were harvested from $3 \mathrm{~d}$ agar cultures containing $1 \%(\mathrm{w} / \mathrm{v})$ glucose or fructose in the presence or absence of dGlc, suspended in basal medium and exposed to $\left[{ }^{14} \mathrm{C}\right] \mathrm{dGlc}\left(20 \mu \mathrm{Ci} \mathrm{ml}^{-1}\right)$ for $1 \mathrm{~h}$. Cell-free extracts were obtained by boiling mycelia and centrifuging. The percentage of label released from cells is given in parentheses. Results are expressed as c.p.m. (mg dry wt cells $)^{-1} \pm \mathrm{SE}$; $n=5$.

\begin{tabular}{|c|c|c|c|c|}
\hline & \multicolumn{2}{|c|}{ Glucose-grown mycelia } & \multicolumn{2}{|c|}{ Fructose-grown mycelia } \\
\hline & Glucose & $\begin{array}{l}\text { Glucose }+ \\
\text { dGlc }(1 \%)\end{array}$ & Fructose & $\begin{array}{l}\text { Fructose }+ \\
\text { dGlc }(1 \%)\end{array}$ \\
\hline$\left[{ }^{14} \mathrm{C}\right] \mathrm{dGlc}$ uptake & $641 \pm 73$ & $374 \pm 61$ & $1123 \pm 163$ & $972 \pm 46$ \\
\hline Hot-water-soluble fraction & $625(98)$ & $310(83)$ & $1018(90)$ & $954(98)$ \\
\hline
\end{tabular}


Table 5. Effects of glucose and glucose analogues on enzyme production by M. anisopliae strains 549 and 808

\begin{tabular}{|c|c|c|c|c|c|c|c|c|c|c|c|c|c|c|c|c|c|c|c|c|c|c|}
\hline \multirow[t]{2}{*}{ Carbon source } & \multirow[t]{2}{*}{ Isolate } & \multicolumn{20}{|c|}{ API ZYM tests* } & \multirow{2}{*}{$\begin{array}{c}\operatorname{Pr} 1 \\
(\mu \mathrm{mol} \mathrm{pNA} \\
\left.\min ^{1} \mathrm{ml}^{-1}\right)\end{array}$} \\
\hline & & 1 & 2 & 3 & 4 & 5 & 6 & 7 & 8 & 9 & 10 & 11 & 12 & 13 & 14 & 15 & 16 & 17 & 18 & 19 & 20 & \\
\hline \multirow[t]{2}{*}{$1 \%$ Chitin } & 549 & 0 & $<1$ & 3 & 1 & $<1$ & 4 & 5 & 1 & 2 & 0 & 4 & 4 & $<1$ & $<1$ & $<1$ & 1 & 2 & 1 & 0 & $<1$ & $0 \cdot 37$ \\
\hline & 808 & 0 & 0 & 3 & 2 & 0 & 3 & 5 & $<1$ & 1 & 0 & 5 & 5 & $<1$ & 3 & 0 & 0 & 2 & 1 & 0 & 0 & 0.41 \\
\hline \multirow[t]{2}{*}{$1 \%$ Chirin $+2 \%$ glucose } & 549 & 0 & () & 1 & 1 & 0 & 1 & 2 & $<1$ & $<1$ & 0 & 4 & 4 & 0 & 0 & 0 & 0 & $<1$ & 1 & 0 & 0 & $(\theta-0) 2$ \\
\hline & 808 & 0 & 0 & 1 & $<1$ & 0 & 0 & $<1$ & 0 & 0 & 0 & 2 & 2 & 0 & 1 & 0 & 0 & 0 & $<1$ & 0 & 0 & $0 \cdot 05$ \\
\hline \multirow[t]{2}{*}{$1 \%$ Chitin $+11 \cdot 2 \%$ dGlc } & 549 & 0 & 0 & 2 & 1 & $<1$ & 1 & 2 & $<1$ & 0 & 0 & 4 & 4 & () & 0 & 0 & 0 & $<1$ & $<1$ & 0 & 0 & 0.014 \\
\hline & 808 & 0 & 0 & 2 & 1 & 0 & $<1$ & 2 & $<1$ & $<1$ & 0 & 4 & 5 & 0 & 2 & 0 & 0 & 1 & $<1$ & 0 & 0 & 0054 \\
\hline \multirow[t]{2}{*}{$1 \%$ Chitin $+2 \% \mathrm{dGlc}$} & 549 & 0 & 0 & 2 & 1 & 0 & 1 & 2 & $<1$ & 0 & 0 & 4 & 4 & 0 & 0 & 0 & 0 & $<1$ & 0 & 0 & 0 & 0.014 \\
\hline & 808 & 11 & 0 & 2 & $<1$ & 0 & 1 & 2 & $<1$ & $<1$ & 0 & 3 & 2 & 0 & 1 & 0 & 0 & 1 & 0 & 0 & 0 & 0.014 \\
\hline $1 \%$ Chitin + & 549 & 0 & 0 & $<1$ & 1 & $<1$ & 2 & 4 & $<1$ & 2 & 0 & 4 & 4 & $<1$ & 0 & $<1$ & $<1$ & 1 & 1 & 0 & 0 & 0.33 \\
\hline $2 \% 3 \cdot 0$-ncthylglucose & 808 & 0 & 0 & 2 & 1 & ( & 2 & 4 & 1 & 1 & 0 & 5 & 5 & 0 & () & 0 & 0 & 1 & 1 & 0 & $<1$ & $0 \cdot 32$ \\
\hline
\end{tabular}

*API ZYM tests. 1, Control; 2, phosphatase alkaline; 3, esterase $\left(C_{4}\right) ; 4$, esterase lipase $\left(C_{8}\right) ; 5$, lipase $\left(C_{14}\right) ; 6$, leucine aminopeptidase; 7 , valine aminopeptidase; 8 , cysteine aminopeptidase; 9 , trypsin; 10 , chymotrypsin; 11 , phosphatase acid; 12 , phosphoamidase; 13 , $\alpha$ galactosidase; 14, $\beta$-galactosidase; 15, $\beta$-glucuronidase; $16, \alpha$-glucosidase; $17, \beta$-glucosidase; $18, \beta$-glucosaminidase; $19, \alpha$-mannosidase; 20 , $\alpha$-fucosidase. Number values $1-5$ indicate increasing colour intensity. Assays against the Pr1 substrate Su-(Ala) ${ }_{2}$-Pro-Phe-pNA, were performed at $23{ }^{\circ} \mathrm{C}$ in $10 \mathrm{mM}$ Tris $/ \mathrm{HCl}, \mathrm{pH} 8,4 \%$ (by vol.) dimethylsufoxide and $0.06 \mathrm{mM}$ substrate. Activities were determined in $5 \mathrm{~h}$ chitin culture filtrates. Phosphoamidase production by $M$. anisopliae strain 549 varied from moderate to strongly positive in different culture flasks. This was the only reaction which varied substantially (by more than one grade) on repeated testing with any of the isolates.

it accumulated in cells without being metabolized (not shown).

\section{Glucose-repressible enzymes}

The results in the previous section suggest that the resistance of strain 808 to dGlc is not simply explained by reduced sugar transport compared with strain 549 . To test whether strains 808 and 549 differ in some aspect of carbon regulation, we assayed a variety of enzymes, including the $\operatorname{Pr} 1$ protease known to be glucose repressible in M. anisopliae (St Leger et al., 1988). Both strains produced high levels of Pr1 in chitin cultures (Table 5). Jevels of Pr1 were greatly reduced in chitin cultures supplemented with glucose or dGlc. By contrast, 3-O-methylglucose allowed derepression of $\operatorname{Pr} 1$ by strains 549 and 808 . Glucose repression was also observed for both strains in esterase, aminopeptidase, and $\beta$-glucosidase activities assayed with the API-ZYM system (Table 5). Acid phosphatase and phosphoamidase production by strain 549 were resistant to glucose repression.

\section{Strain differences in $M$. anisopliae}

Data from a comparative study of germination and growth of 26 isolates on different carbon sources are shown in Table 6 . As reported previously (St Leger $e t a l$., 1992), lines isolated from Coleoptera, particularly scarabaeids, are frequently less adaptable than other isolates with little germination on glucose, and sometimes YEM. Of the 18 lines showing less than $30 \%$ germination on glucose media, 13 were isolated from coleopterans. Growth of these isolates on fructose media was reduced by an average of $33 \%$ by incorporation of $1 \%$ dGIc. Five of the eight lines showing good $(>30 \%)$ germination on glucose were isolated from Lepidoptera and Homoptera. Mean growth of these lines was reduced by $70 \%$ by dGlc.
A second glucose analogue, L-sorbose, also reduced growth of most dGlc-susceptible isolates; exceptionally strains 549 and 1066 were resistant to sorbose. Conversely, the dGlc resistant isolate 760 was susceptible to sorbose. 3-O-Methylglucose did not affect the growth characteristics of any of the isolates in fructose media (data not shown).

\section{DISCUSSION}

As strains 549 and 808 differed in their ability to germinate rapidly on glucose, we tested well-characterized glucose analogues (Eraso \& Gancedo, 1985; Moore, 1981) that are phosphorylated but not extensively metabolized (e.g. dGlc) and sugars that can only be transported into the cell (6-deoxyglucose and 3-O-methylglucose) to determine to what extent a sugar should be metabolized to allow germination and catabolite repression. The conidia of $M$. anisopliae strain 549 germinate rapidly in response to exogenous glucose. In conidia of several other fungal systems, glucose acts as a positive effector of germination without metabolism by causing an increase in cAMP content, which in turn initiates an enzyme cascade (Van Mulders \& Laere, 1984). This apparently requires a functional glucose transport system (Beullens et al., 1988). Other factors must also be necessary in strain 549 as nonmetabolizable analogues were transported but did not trigger germination. Also, uptake of dGlc was competed for by glucose and 6-deoxyglucose which therefore probably utilized the same transport system. Glucose and fructose are transported through the same carrier in Saccharomyces cerevisiae (Schuddemat et al., 1988). By contrast, in $M$. anisopliae, fructose was much less able than glucose to inhibit uptake of dGlc indicating that fructose may be taken up by a different transport system than that for glucose. Consequently, dGlc inhibited growth of $M$. anisopliae to a greater extent on frucose-based media than 
Table 6. Frequency (\%) of germination of each of 26 isolates of $M$. anisopliae (incubated $24 \mathrm{~h}$ ) in yeast extract medium (YEM) or glucose and their ability to grow on Czapek Dox agar or fructose agar medium with or without dGlc or sorbose, $4 \mathrm{~d}$ after inoculation

The growth results are means $\pm S E$ of four replicates per test. The numbers in parentheses are the percentage growth in the presence of sorbose or dGlc compared with unsupplemented Czapek Dox or fructose agar media.

\begin{tabular}{|c|c|c|c|c|c|c|c|c|}
\hline \multirow[t]{2}{*}{ Strain } & \multirow[t]{2}{*}{ Host } & \multicolumn{2}{|c|}{ Germination (\%) } & \multicolumn{5}{|c|}{ Growth (mm) } \\
\hline & & $\begin{array}{c}\text { YEM } \\
(0.02 \%)\end{array}$ & $\begin{array}{c}\text { Glucose } \\
(0.5)\end{array}$ & \multicolumn{3}{|c|}{$\mathrm{CzD}$} & \multicolumn{2}{|c|}{ Fructose $(1 \%)$} \\
\hline 1946 & Coleoptera & $<1$ & 0 & $5 \cdot 5 \pm 0 \cdot 1$ & $1 \cdot 0 \pm 0(18 \cdot 2)$ & $1 \cdot 0 \pm 0(19 \cdot 2)$ & $6 \cdot 3 \pm 0 \cdot 1$ & $2 \cdot 5 \pm 0(39 \cdot 7)$ \\
\hline 1946 & Coleoptera & $<1$ & $<1$ & $5 \cdot 5 \pm 0.05$ & $1 \cdot 0 \pm 0(18 \cdot 2)$ & $1 \cdot 0 \pm 0(18 \cdot 2)$ & $6 \cdot 0 \pm 0 \cdot 2$ & $2 \cdot 5 \pm 0(41 \cdot 7)$ \\
\hline 2165 & Coleoptera & 2 & $<1$ & $7 \cdot 5 \pm 0 \cdot 2$ & $0.5 \pm 0(6 \cdot 7)$ & $2 \cdot 0 \pm 0(36 \cdot 4)$ & $6 \cdot 5 \pm 0 \cdot 2$ & $2 \cdot 0 \pm 0(30 \cdot 8)$ \\
\hline 297 & Coleoptera & 1 & 0 & $4 \cdot 7 \pm 0 \cdot 2$ & $0.5(10 \cdot 6)$ & $0 \cdot 5 \pm 0(10 \cdot 6)$ & $7 \cdot 5 \pm 0 \cdot 2$ & $2 \cdot 0 \pm 0(42 \cdot 3)$ \\
\hline 1015 & Lepidoptera & 1 & 1 & $12 \cdot 8 \pm 0 \cdot 4$ & $7 \cdot 2 \pm 0 \cdot 2(56 \cdot 3)$ & $4 \cdot 3 \pm 0 \cdot 1(33 \cdot 6)$ & $12 \cdot 6 \pm 0 \cdot 5$ & $6 \cdot 5 \pm 0 \cdot 4(51 \cdot 6)$ \\
\hline 1066 & Coleoptera & 4 & 1 & $6 \pm 0 \cdot 2$ & $5.5 \pm 0.05(91.7)$ & $2 \cdot 0 \pm 0(33 \cdot 3)$ & $5 \cdot 5 \pm 0 \cdot 1$ & $1 \cdot 2 \pm 0(21 \cdot 8)$ \\
\hline 760 & Coleoptera & 23 & 1 & $11 \cdot 8 \pm 0 \cdot 3$ & $2 \cdot 5 \pm 0(21 \cdot 2)$ & $9 \cdot 3 \pm 0 \cdot 2(78 \cdot 8)$ & $11 \cdot 1 \pm 0 \cdot 4$ & $9 \cdot 2 \pm 0 \cdot 4(82 \cdot 9)$ \\
\hline 1080 & Lepidoptera & 24 & 1 & $11 \cdot 4 \pm 0 \cdot 2$ & $3 \cdot 3 \pm 0 \cdot 05(4 \cdot 3)$ & $10 \cdot 5 \pm 0 \cdot 2(4 \cdot 4)$ & $11 \cdot 5 \pm 0.4$ & $7 \cdot 3 \pm 0 \cdot 2(63 \cdot 5)$ \\
\hline 1187 & Lepidoptera & 22 & 6 & $7 \cdot 1 \pm 0 \cdot 3$ & $3 \cdot 2 \pm 0.05(45 \cdot 1)$ & $3 \cdot 2 \pm 0 \cdot 05(45 \cdot 1)$ & $7 \cdot 0 \pm 0 \cdot 3$ & $5 \cdot 6 \pm 0 \cdot 3(80 \cdot 0)$ \\
\hline 755 & Hemiptera & 18 & 8 & $10 \cdot 5 \pm 0 \cdot 2$ & $2 \cdot 5 \pm 0(23 \cdot 8)$ & $8 \cdot 1 \pm 0 \cdot 2(77 \cdot 1)$ & $9 \cdot 4 \pm 0 \cdot 3$ & $9 \cdot 4 \pm 0 \cdot 2(100)$ \\
\hline 808 & Coleoptera & 75 & 4 & $9 \cdot 3 \pm 0 \cdot 3$ & $9 \cdot 0 \pm 0.3(96.8)$ & $7 \cdot 3 \pm 0 \cdot 2(78 \cdot 5)$ & $8 \cdot 5 \pm 0.4$ & $8.3 \pm 0.3(97 \cdot 6)$ \\
\hline 2575 & Coleoptera & 80 & 14 & $11 \cdot 7 \pm 0 \cdot 2$ & $8.5 \pm 0.3(72.6)$ & $1 \cdot 3 \pm 0.5(11 \cdot 1)$ & $10 \cdot 3 \pm 0 \cdot 4$ & $9 \cdot 5 \pm 0.4(92 \cdot 2)$ \\
\hline 939 & Coleoptera & 28 & 36 & $14 \cdot 3 \pm 0 \cdot 3$ & $6 \cdot 4 \pm 0 \cdot 2(44 \cdot 8)$ & $0 \cdot 5 \pm 0(3 \cdot 5)$ & $13 \cdot 4 \pm 0 \cdot 6$ & $0.5 \pm 0(3 \cdot 7)$ \\
\hline 1892 & Homoptera & 74 & 63 & $9 \cdot 5 \pm 0 \cdot 1$ & $4 \cdot 5 \pm 0 \cdot 1(47 \cdot 4)$ & $10 \cdot 5 \pm 0(5 \cdot 3)$ & $9 \cdot 5 \pm 0.5$ & $0 \cdot 5 \pm 0(5 \cdot 3)$ \\
\hline 23 & Coleoptera & 72 & 47 & $8 \cdot 3 \pm 0 \cdot 2$ & $2 \cdot 5 \pm 0(30 \cdot 1)$ & $4 \cdot 2 \pm 0 \cdot 2(50 \cdot 6)$ & $5 \cdot 5 \pm 0 \cdot 4$ & $4 \pm 0 \cdot 1(72 \cdot 7)$ \\
\hline 988 & Lepidoptera & $>80$ & 75 & $7 \cdot 7 \pm 0 \cdot 2$ & $10 \cdot 5 \pm 0(7 \cdot 0)$ & $4 \cdot 2 \pm 0 \cdot 1(59 \cdot 2)$ & $6 \cdot 3 \pm 0 \cdot 3$ & $0 \cdot 5 \pm 0(7 \cdot 9)$ \\
\hline 552 & Lepidoptera & $>80$ & $>80$ & $10 \cdot 4 \pm 0 \cdot 2$ & $3.0 \pm 0.05(28 \cdot 8)$ & $0 \cdot 5 \pm 0(4 \cdot 8)$ & $6 \cdot 1 \pm 0 \cdot 2$ & $0 \cdot 5 \pm 0(8 \cdot 2)$ \\
\hline
\end{tabular}

on those containing glucose. Dillon \& Charnley (1990) found that methylglucose promotes protein synthesis in swollen (water-soaked) spores of $M$. anisopliae but high levels of germination required a utilizable carbon source. This suggests that, though glucose may act as a trigger, its metabolism is also important for germination.

Cyclic AMP itself is usually ineffective when applied exogenously to fungi, probably because of low penetration by this hydrophilic and negatively charged compound (Pall, 1981). Where cAMP or its analogues are effective at influencing fungal growth, it is implicitly assumed that this is due to activation of cAMP-dependent kinases (Pall, 1981). However, cAMP and the non-cyclic nucleotide adenosine supported growth of strain 549 indicating both uptake and utilization of the nucleotides as carbon sources. By contrast, only short germ-tubes were produced in the presence of IBMX, indicating that lowering the phosphodiesterase activity triggers germi- nation by affecting intracellular levels of cAMP. 6Deoxyglucose increased germination when applied with IBMX. The same combination increased intracellular cAMP levels when applied to Pilobolus longipes spores (Bourret, 1986).

In a previous study utilizing an $M$. anisopliae line (ARSEF 2575) isolated from a beetle we found cAMP in ungerminated conidia and the pre-germination synthesis of cAMP target proteins (St Leger et al., 1990a, b). However, their role appeared to be minor compared with a $\mathrm{Ca}^{2+} /$ calmodulin-dependent kinase which serves to modulate the effects of $\mathrm{Ca}^{2+}$ on the system and triggers germination (St Leger et al., 1990a, b, 1991). In contrast to glucose, nitrogen-source-induced trehalase activation is not mediated by cAMP in the yeast $S$. cerevisiae (Thevelein $\&$ Beullens, 1985) and we suggested there may be a connection between the regulatory mechanisms observed in line 2575 conidia and their poor germination on 
glucose as compared with germination on nitrogen sources (St Leger et al., 1990b, 1992). Line 808 resembles strain 2575 in being isolated from a beetle and showing slow germination on glucose as compared with alanine or YEM. Unlike strain 2575, it is in the same genotypic class as line 549 which allows us to assume a similar genetic background.

The two lines, 808 and 549, most clearly resemble each other in the ability of glucose to inhibit the derepression of a number of catabolite repressible enzymes including the pathogenicity determinant $\operatorname{Pr} 1$. The same effect was produced by dGlc indicating that metabolism of the sugar beyond the sugar phosphate step is not necessary. By contrast, 3-O-methylglucose did not affect enzyme production, demonstrating a need for hexokinase phosphorylation of the sugar after transport. Up to now, no clear evidence exists on the nature of the signal(s) produced by glucose to cause catabolite repression in yeasts (Gancedo, 1992). However, genetic studies have shown that the primary trigger of the cAMP signal in $S$. cerevisiae is at the level of transport and/or phosphorylation of the sugar (Beullens et al., 1988). They suggest that a glucose transport protein/kinase complex interacts with adenylate cyclase. Recent data have shown that a GTP binding protein regulates the cAMP signal in M. anisopliae (St Leger et al., 1991) and presumably would mediate this interaction. However, cAMP does not by itself affect $\operatorname{Pr} 1$ production in $M$. anisopliae (2575) ( $\mathrm{St}$ Leger et al., 1988) so it is possible that the carrier/kinase complex interacts with several regulatory proteins to trigger specific cellular events. These results suggest that dGlc will be useful in subsequent studies on the phenomenon of catabolite repression in $M$. anisopliae, particularly in those isolates such as 808 where it is not toxic.

The biochemical basis of dGlc resistance in strain 808 is not yet clear. Conidia of strain 808 transport dGlc at a $30 \%$ reduced rate compared to strain 549. However, the resistance of strain 808 cannot be explained simply by a reduction in sugar transport given that both isolates were efficient sugar fermenters using many sugars as sole carbon sources indicative of several intact transport systems and metabolic pathways. Phosphorylation of dGIc can deplete intracellular ATP, an effect which may contribute to the toxic effects of dGlc (Bourret, 1987), but strains 549 and 808 appear to metabolize dGlc similarly to 2-deoxyglucose phosphate indicating that neither is altered in phosphorylation or phosphatase activities. This indicates that energy must be expended continuously during growth of strain 808 to maintain an intracellular pool of $\mathrm{dGlcPO}_{4}$.

Many of the strains of $M$. anisopliae which germinated well on glucose were particularly susceptible to dGlc. It is doubtful whether any inhibition of sugar uptake by dGlc could be a major component of the growth inhibition since dGlc causes inhibition of growth of strain 549 on media containing alanine or glycerol. It is tempting, therefore, to speculate that the toxic effect of dGlc on strain 549 and its ability to germinate rapidly on glucose are linked, presumably because dGlc is being used in metabolism in place of glucose. It is well established that $\mathrm{dGlcPO}_{4}$ weakens the cell wall of yeasts by adversely affecting the incorporation of glucose into wall polysaccharides (Moore, 1981). Microscopic examination of strain 549 revealed no evidence for lysis of hyphal tip cells. Also, analysis of hot water cell extracts revealed that very little dGlc or its metabolites were trapped by being incorporated directly into the cell walls of $M$. anisopliae as occurs in S. cerevisiae (Krátky et al., 1975). Any dGlcinduced effects on the cell wall of $M$. anisopliae are likely to be indirect by interference of phosphorylated metabolites with metabolic processes involved in cell wall synthesis. Morphological changes in $M$. anisopliae (e.g. formation of appressoria) result from changes in cell wall synthesis and possibly turgor pressure (St Leger et al., 1991). It is possible that dGlc (in alanine media) induced swelling of the tip cells of strain 549 hyphae and production of blastospore-like structures by weakening the cell walls resulting in osmotic fragility. It is also possible that the change in cell shape results from alterations in wall synthesis directed by endogenous respiratory events. In any event, dGlc may be useful in determining the metabolic functions associated with these morphological changes.

dGlc has proved useful for the isolation of catabolite repression mutants of S. cerevisiae (Zimmermann \& Scheel, 1977) and filamentous fungi (Moore, 1981; Allen et al., 1989; Kirimura et al., 1992). These mutants display pleiotropic alterations in enzymes that are normally glucose-repressible. Similarly, dGlc-resistant mutants of Neurospora crassa were also resistant to sorbose (Allen et al., 1989). Some, but not all, dGlc-resistant strains of $M$. anisopliae were cross-resistant to sorbose as well, suggesting possible allelism. It is likely that dGlc would appear toxic to strain 549 if it interfered with the derepression of the enzymes needed for utilization of fermentable carbon sources. Also, strain 808, but not strain 549, grew well with dGlc in glycerol medium, a non-fermentable substrate, the utilization of which requires glucose derepression of enzymes of the TCA cycle (Johnson \& Carlson, 1992). It is noteworthy that dGlc altered morphogenetic events of strain 808 on solid media including the formation of aerial hyphae and conidiation. Fluoroacetate (a Krebs cycle inhibitor) causes similar alterations (unpublished data). It is possible, therefore, that dGlc affects the balance between fermentation and oxidative pathways for carbohydrate utilization in strain 808.

The fact that glucose and dGlc repress Pr1 production by strain 808 suggests that catabolite repression can be divided into different segments. The slow response of line 808 conidia to glucose in the medium is presumably due to one of the components in the chain from glucose to germination being dormant or less active. This assumes a relatively small difference at the molecular level. We are currently investigating glucose-repressible proteins involved in the germination of strains 549 and 808 . In particular, the physiological effects of IBMX on germination are causing us to focus our attention on phosphodiesterase activities in spores. 


\section{ACKNOWLEDGEMENTS}

This work was supported in part by a grant (92-37302-7791) from the USDA Competitive Research Grants Office.

\section{REFERENCES}

Allen, K. E., McNally, M. T., Lowendorf, H. S., Slayman, C. W. \& Free, S. J. (1989). Deoxyglucose-resistant mutants of Neurospora crassa: isolation, mapping, and biochemical characterization. $J$ Bacteriol 171, 53-58.

Beullens, M., Mbonyi, K., Geerts, L., Gladines, D., Detremerie, K., Jans, A. W. H. \& Thevelein, J. M. (1988). Studies on the mechanism of the glucose-induced cAMP signal in glycolysis of glucose repression mutants of the yeast Saccharomyces cerevisiae. Eur J Biochem 172, 227-231.

Bourret, J. A. (1985). Glucose transport by germinating Pilobolus longipes spores. Exp Mycol 9, 48-55.

Bourret, J. A. (1987). The mechanism by which 2-deoxyglucose inhibits glucose-induced activation of Pilobolus longipes spores. Exp Mycol 11, 307-316.

Dillon, R. J. \& Charnley, A. K. (1990). Initiation of germination in conidia of the entomopathogenic fungus, Metarbizium anisopliae. Mycol Res 94, 299-304.

Eraso, P. \& Gancedo, J. M. (1985). Use of glucose analogues to study the mechanism of glucose-mediated cAMP increase in yeast FEBS Lett 191, 51-54.

Gancedo, J. M. (1992). Carbon catabolite repression in yeast. Eur J Biocbem 206, 297-313.

Johnson, M. \& Carlson, M. (1992). Regulation of carbon and phosphate utilization. In The Molecular and Cellular Biology of the Yeast Sacharomyces, pp. 193-282. Cold Spring Harbor Laboratory: Cold Spring Harbor Laboratory Press.

Kirimura, K., Sarangbin, S., Rugsaseel, S. \& Usami, S. (1992). Citric acid production by 2-deoxyglucose-resistant mutant strains of Aspergillus niger. Appl Microbiol Biotecbnol 36, 573-577.

Krátky, Z., Biely, P. \& Bauer, S. (1975). Mechanism of 2-deoxy-Dglucose inhibition of cell wall polysaccharide and glycoprotein biosynthesis in Saccharomyces cerevisiae. Eur J Biocbem 54, 459-467.

Moore, D. (1981). Effects of hexose analogues on fungi: mechanisms of inhibition and resistance. New Pbytologist 87, 487-515.

Pall, M. L. (1981). Adenosine 3', $5^{\prime}$-phosphate in fungi. Microbioi Rev 45, 462-480.

Schuddemat, J., Van den Broek, P. J. A. \& Van Steveninck, J. (1988). The influence of ATP on sugar uptake mediated by the constitutive glucose carrier of Saccharomyces cerevisiae. Biocbim Bicphys Acta 937, 81-87.
St Leger, R. J., Charnley, A. K. \& Cooper, R. M. (1986a). Cuticledegrading enzymes of entomopathogenic fungi: synthesis in culture on cuticle. J Invertebr Patbol 48, 85-95.

St Leger, R. J., Charnley, A. K. \& Cooper, R. M. (1986b). Enzymatic characterization of entomopathogens with the API ZYM system. J. Invertebr Pathol 48, 375-376.

St Leger, R. J., Durrands, P. K., Cooper, R. M. \& Charnley, A. K. (1988). Regulation of production of proteolytic enzymes by the entomopathogenic fungus Metarbizium anisopliae. Arch Microbiol 150, 413-416.

St Leger, R. J., Roberts, D. W. \& Staples, R. C. (1989a). Novel GTP-binding proteins in plasma membranes of the fungus Metarbizium anisopliae. Biochem Biopbys Res Comm 164, 562-566.

St Leger, R. J., Roberts, D. W. \& Staples, R. C. (1989b). Calcium and calmodulin-mediated protein synthesis and protein phosphorylation during germination, growth and protease production by Metarbizium anisopliae. J Gen Microbiol 135, 2141-2154.

St Leger, R. J., Laccetti, L. B., Staples, R. C. \& Roberts, D. W. (1990a). Protein kinases in the entomopathogenic fungus Metarbizium anisopliae. J Gen Microbiol 136, 1401-1411.

St Leger, R. J., Butt, T. M., Staples, R. C. \& Roberts, D. W. (1990b). Second messenger involvement in differentiation of the entomopathogenic fungus Metarbizium anisopliae. J Gen Microbiol 136, 1779-1789.

St Leger, R. J., Roberts, D. W. \& Staples, R. C. (1990C). Electrophoretic detection of multiple protein kinases in the entomopathogenic fungus Metarbizium anisopliae. Arch Microbiol 154, 518-520.

St Leger, R. J., Roberts, D. W. \& Staples, R. C. (1991). A model to explain differentiation of appressoria by germlings of Metarbizium anisopliae. J Invertebr Patbol 57, 299-310.

St Leger, R. J., May, B., Allee, L. L., Frank, D. C. \& Roberts, D. W. (1992). Genetic differences in allozymes and in formation of infection structures among isolates of the entomopathogenic fungus Metarbizium anisopliae. J Invertebr Patbol 60, 89-101.

Thevelein, J. M. \& Beullens, M. (1985). Cyclic AMP and the stimulation of trehalase activity in the yeast Saccharomyces cerevisiae by carbon sources, nitrogen sources and inhibitors of protein synthesis. J Gen Microbiol 131, 3199-3209.

Van Mulders, R. M. \& Van Laere, A. J. (1984). Cyclic AMP, trehalose and germination of Phycomyces blakesleeanus spores. J. Gen Microbiol 130, 540-547.

Zimmermann, F. K. \& Scheel, I. (1977). Mutants of Saccharomyces cerevisiae resistant to carbon catabolite repression. Mol \& Gen Genet $154,75-82$.

Received 15 November 1993; revised 1 February 1994; accepted 7 February 1994. 